\title{
Inconexión o desconocimiento: Profesionales en educación preescolar y la didáctica de una lengua extranjera
}

\author{
Disconnection or Unawareness: Professionals in Preschool Education and the Didactic of a \\ Foreign Language
}

\section{Inconexão ou desconhecimento: Profissionais de educação infantil e a didática de uma língua estrangeira}

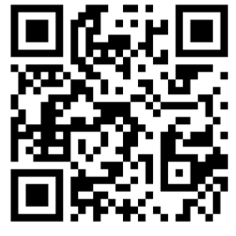

Corregido • Revised • Revisado: 27 / 08 / 2021

Aceptado • Accepted • Aprovado: 23 / $11 / 2021$

\begin{abstract}
Resumen:
Objetivo. El presente texto tiene como propósito exponer la importancia que tiene el conocimiento sobre la teoría y práctica de la enseñanza del inglés como lengua extranjera, por parte del personal docente de educación inicial. Metodología. La investigación en cuestión tuvo como nombre Formación pedagógica de los profesionales en educación inicial y su relación con la didáctica en un contexto internacional. A su vez, se acogió a un paradigma cualitativo para poner de manifiesto los efectos y datos de las encuestas, al igual que de las declaraciones expresadas por las unidades de análisis, a las cuales se les aplicaron entrevistas semi-estructuradas y fueron parte de juntas para grupos focales. En cuanto a las participantes, se trabajó con 200 profesionales en educación inicial (100 de Colombia y 100 de México). Resultados. Entre los resultados más preponderantes, se encontró que se deben implementar cursos sobre la didáctica en la enseñanza del inglés en niños y niñas, para los pregrados referentes a la formación de profesionales en educación inicial; y, por otro lado, también se halló el fenómeno de prioridad en contrataciones a profesionales en inglés -para dar clases en educación preescolar- en comparación a docentes profesionales en educación inicial. Conclusiones. Los certificados de nivel de inglés, post-universidad, que obtuvieron las profesionales
\end{abstract}


http://doi.org/10.15359/ree.26-1.18

http://www.una.ac.cr/educare

educare@una.ac.cr

en educación inicial, no garantizaron en ellas conocimiento didáctico para la enseñanza de esta lengua a niños y niñas. Asimismo, los saberes acerca de teorías y enfoques pedagógicos en general, no son suficiente herramienta para suplir los faltantes en la enseñanza de este idioma.

Palabras claves: Profesores; método; enseñanza; educación parvularia, inglés.

\begin{abstract}
:
Objective. This paper aims to show how important theoretical knowledge is for the theory and practice of teaching English -as a foreign language- for early childhood teachers. Method. The respective research was named Pedagogical training of professionals in early childhood education and how it is related to didactics in an international context. Likewise, a qualitative paradigm was used to present the effects and data collected from the surveys and the statements from the units of analysis that took part in the semi-structured interviews and focus groups. The participants were 200 professionals in early childhood education (100 from Colombia and 100 from Mexico). Results. Among the most meaningful results, it was found that it is necessary to implement didactic courses about teaching English to children in undergraduate degrees related to training professionals for early childhood education. Moreover, it was visible the phenomenon of giving priority to hiring English teachers -to teach in preschool- compared to employing early childhood teachers. Conclusions. The English levels certificates that the early childhood teachers obtained, apart from their studies in the university, did not guarantee any didactic knowledge to teach this language to children. Similarly, all kinds of knowledge about theory and pedagogical approaches, in general, are tools considered not sufficient to supply the gaps in the teaching practice in this language.
\end{abstract}

Keywords: Teachers; method; teaching; preschool education; English.

\title{
Resumo:
}

Objetivo. O objetivo deste texto é expor a importância do conhecimento sobre teoria e prática de ensinar inglês como língua estrangeira, pelos professores da educação inicial. Metodologia. A investigação em questão foi nomeada Formação pedagógica de profissionais da educação inicial e sua relação com a didática em um contexto internacional. Da mesma forma, um paradigma qualitativo foi adotado para revelar os efeitos e dados das entrevistas, ao igual que as declarações expressas pelas unidades de análise, às quais foram aplicadas entrevistas semiestruturadas e fizeram parte de reuniões de grupos focais. Em relação com as participantes, o trabalho foi feito com 200 profissionais em educação infantil (100 da Colômbia e 100 do México). Resultados. Entre os resultados mais importantes, sinaliza a necessidade de oferecer cursos sobre a didática do inglês para crianças, para o bacharelato referente a formação de profissionais em educação inicial; e por outro lado, também foi encontrado o fenômeno de priorizar a contratação de docentes de inglês para ensinar na etapa de educação infantil, em comparação com docentes profissionais na educação infantil. Conclusão. Os certificados de nível de inglês, pós-universidade, obtidos pelos profissionais na educação infantil, não garantem neles o conhecimento didático para o ensino desta língua as crianças. Além disso, o conhecimento sobre teorias e abordagens pedagógicas em geral não são ferramentas suficientes para preencher as lacunas no ensino deste idioma.

Palavras-chave: Professores método; ensino; educação infantil; inglês. 
http://doi.org/10.15359/ree.26-1.18

\section{Introducción}

La enseñanza es un ejercicio en desarrollo a lo largo del tiempo, con múltiples variantes a través del mismo, y con mujeres y hombres como protagonistas. Asimismo, con el pasar de las décadas, emergen una serie de terminologías afines a esta labor: aprendizaje, didáctica, técnica, estrategia, recursos, lúdica, materiales, metodología, método, y demás. Se establece que "la mayor parte de las investigaciones en educación superior emergen del interés por estudiar aspectos básicos del proceso de enseñanza y aprendizaje, particularmente de los métodos de adquisición y construcción del conocimiento" (Rojas-Jara et al., 2016, p. 3). Así pues, este artículo hace hincapié en la relación que existe entre la enseñanza y algunos de esos conceptos, específicamente hablando de la didáctica y el inglés en educación preescolar; situación que merece la atención para una mejor comprensión de lo que este fenómeno representa en la comunidad educativa en general.

A su vez, el estudio que sirvió como base para la escritura de este texto, circundó en temas relacionados a los procederes didácticos que las docentes en educación inicial (participantes del estudio) Ilevaban a cabo en su quehacer profesional. En suma, lo referente a la importancia de la formación en didáctica, lúdica, enseñanza con base en las teorías del desarrollo humano, saberes previos, entre otros (Soto-Grant, 2018). Consecuentemente, además de presentar una serie de hallazgos por parte de la investigación en cuestión, este artículo pretende servir a aquel personal docente que esté interesado en cualificar sus respectivas prácticas educativas.

A continuación, es necesario definir ciertos conceptos relativos al aprendizaje del inglés como lengua extranjera; por lo tanto, se dará comienzo a precisar la concepción de la enseñanza, para así entender y diferenciar lo que se entiende por esta palabra tan problemática.

\section{Fundamentación teórica}

Para comenzar a clarificar lo connatural de este texto, se selecciona el término enseñanza. La palabra enseñar es una derivación del latín insignare, in (en) y signare señalar o apuntar hacia. Esta acción es entendida como la idoneidad de orientar a alguien por el sendero o camino que debe recorrer. El acto de enseñar llega a ser desarrollado por personas que tengan un conocimiento o saber definido, saber que puede ser brindado o dado a conocer a través del lenguaje. Se plantea, entonces, que "Enseñar es un acto cultural que se da en el tiempo. Desde este enfoque hay que entender que enseñar es exponerse -un aspecto de la [sociedad]-, en la forma que sea (virtualmente, por escrito o de manera presencial)" (Laudo Castillo et al., 2017, p. 88).

El acto de la enseñanza se decanta por los saberes culturales de las sociedades. La escuela incluye en sus planes de estudio todo tipo de temas relacionados a los entornos particulares y generales, y estos temas se alcanzan por medio de objetivos y competencias a desarrollar de distintas formas, ya sea presencial o virtual. En lo que concierne al acto de enseñar, también se puede decir que: 
http://doi.org/10.15359/ree.26-1.18

http://www.una.ac.cr/educare

educare@una.ac.cr

La enseñanza es la actividad y el proceso que generan los docentes; algunos se encuentran profundamente preocupados por los contenidos, por generar acciones que posibiliten el aprendizaje de sus alumnos; otros, por diversas circunstancias, han alterado el deseo de seguir aprendiendo y conociendo. (Espinosa Jiménez, 2018, p. 143)

Este ávido procedimiento involucra a múltiples personas actoras, pero, como principales, a profesores y estudiante, por lo cual, demanda interacción de las formas posibles. En este sentido, existe una influencia bidireccional, contrario a lo que se cree comúnmente (unidireccional de maestro a alumno), ya que el estudiantado, con sus particularidades, hace que el peronal docente planee sus clases con intencionalidades; a su vez, cuando el personal docente -por medio de la clase- permite que el estudiantado desarrolle sus competencias, está ejerciendo una influencia sobre este: "la valoración de la docencia pasa por la actitud de cada docente (vocación y pasión por la enseñanza), el trato que tiene hacia el estudiantado y la enseñanza centrada en el alumnado" (Orellana-Fernández et al., 2018, p. 14). Algunos autores definen la enseñanza como una ciencia, otros como una disciplina y otros como un arte; al respecto, Llera (1995) afirma que "En realidad, la enseñanza es ambas cosas a la vez, un arte y una ciencia. Como arte, la enseñanza seguramente compromete las emociones, los valores y el espíritu de todo el que enseña bien" (p. 19).

Ya sea como arte o ciencia, la enseñanza siempre debe llevar consigo una dosis de ética, debido a que el hecho de concentrar toda la atención en lo cognitivo, reproduciría muchos de los infortunios que han carcomido a la sociedad en la historia; y que, aún hoy por hoy, se ven reflejados en la corrupción y maldad patológica de muchos seres humanos que pasan inadvertidos los procesos de lucha y sacrifico de la vida para cobijarse con la codicia y el poder por medio de atajos bastante dudosos (Cifuentes Londoño et al., 2019). Si bien, la enseñanza debe brindar saberes, también debe brindad libertad, libertad para vivir, crear y tomar decisiones. Con base en lo anterior, Freire (1994) manifiesta que "La tarea de enseñar es una tarea profesional que exige amorosidad, creatividad, competencia científica, pero rechaza la estrechez cientificista, que exige la capacidad de luchar por la libertad sin la cual la propia tarea perece" (p. 9).

Los individuos necesitan ser enseñados y acuden a la escuela para que esta haga su aporte, una contribución que es complementada por la familia y la sociedad. No obstante, la escuela solo puede brindar su asistencia hasta donde es menester, ya que muchas actitudes comportamentales obedecen, mayormente, al tiempo que las personas interactúan en el hogar y en la calle. Ahora bien, el profesor debe estar en la capacidad de enseñar para la vida, pues es por medio del conocimiento que el ser humano llega realmente a emanciparse y a ejercer cambios significativos a nivel social.

Luego de precisar el concepto de enseñanza, ahora se dispone a dar definición a la didáctica; la palabra se deriva del griego didaskein que significa 'enseñar' y tékne, entendido como 'arte o talento', dicho de otra manera, 'el arte o talento de enseñar'. Es decir: 
http://doi.org/10.15359/ree.26-1.18

La didáctica es ciencia en cuanto investiga, experimenta y crea teorías sobre cómo enseñar, sobre cómo el docente debe "actuar en la enseñanza", para alcanzar determinadas metas en el alumno, teniendo como base, principalmente, el diálogo interactivo de la Biología, la Psicología, la Sociología y la Filosofía. (Picado Godínez, 2006, p. 102)

Hasta donde es posible, la didáctica pone en acción lo que está en el papel; los objetivos y las competencias que se exhiben para ser alcanzadas y desarrolladas por el estudiantado, y se vuelven vida en una práctica que es precedida por una reflexión, la cual se vuelve interdisciplinar incorporando ciencias y disciplinas rígidas y sociales. Aún así, la didáctica no puede ser entendida como una acción inminente y enconadamente instrumental, pues toda acción en educación carece de sentido sin una previa reflexión. Vale la pena mencionar que "la Didáctica se ocupa de la enseñanza, del aprendizaje, del proceso instructivo y de la formación integral del discente" (Díaz Alcaraz, 2002, p. 44).

La didáctica recoge los procesos de enseñanza-aprendizaje, y todo lo que subyace a estos, para el servicio del que aprende. Se ve reflejada en la planeación y se plasma por medio de las estrategias metodológicas del docente; nunca será un lastre para este, porque lo nutre de herramientas para ser cada vez más preciso en el momento de estar en un aula de clase (Jaramillo Valencia y Quintero, 2018). No se puede soslayar el conocimiento y saber epistemológico del profesor acerca de la pedagogía en relación con la didáctica, por lo tanto, la didáctica está predispuesta al saber y conocimientos. Al respecto, Abreu et al. (2017) afirma que "la didáctica es una respuesta a la necesidad de encontrar un equilibrio que armonice la relación entre las maneras de enseñar de los educadores y el aprendizaje de sus discípulos" (p. 82).

La didáctica -a diferencia de muchas otras prácticas inherentes a la educación- no es un quehacer itinerante; pertenece mayormente a la educación formal, aunque también se puede dar en la educación no formal, y, además, necesita de profesores-pedagogos para ser ejecutada, ya que requiere de conocimientos sobre teorías, corrientes, métodos, enfoques, etc. Saberes que escasamente se perciben en la educación informal.

El siguiente punto trata del inglés como lengua extranjera. Cuando se hace referencia a esta concepción, se debe tener en cuenta que esta ha tenido una historia y una respectiva evolución. Tribus germánicas como los Sajones, Anglos, Jutos, Frisios, entre otras, intervinieron de distintas formas para ir dando contextura a esta lengua, la cual tendría su mayor pluralidad desde la edad media en adelante, pues es aquí cuando los celtas, normandos y franceses despliegan un sincretismo, ya sea, por guerras, alianzas o comercio, para dar más variedad a este idioma. En la época del renacimiento, se toman palabras del griego y del latín, y, tiempo después, desde la revolución industrial en adelante, esta lengua es aún más masificada y permeada, gracias a la tecnología y concepto de industria extendido por el imperio británico: 
http://doi.org/10.15359/ree.26-1.18

http://www.una.ac.cr/educare

educare@una.ac.cr

El inglés es una mezcla de palabras, deletreos, y pronunciaciones que han venido de [muchos lenguajes]. La tendencia es retener el deletreo original aunque el deletreo no cabe el deletreo tradicional del idioma. La mayoría de las palabras toman sus bases en Latín (más o menos 75\%) y el deletreo es similar (y muchas veces igual) al deletreo latino. (Carro, 2011, p. 4)

En lo tocante al dominio lingüístico para algunos, es claro que el inglés se ha visto influenciado por muchas otras lenguas. Es decir, que, a la inversa, el inglés poco ha mediado en el desarrollo de otras. Por tal razón, la correspondencia de lengua que se impone o dominante, es más voluntad de los cambios e intereses económico-sociales, entre los cuales se sitúan los idiomas, conjunto de expresiones inanimadas, creadas por el hombre, que, sea cual fuere la razón, padecen del rechazo o la afinidad de las personas. Por consiguiente, Casares Domingo (2006) expresa que "La historia de la lengua inglesa es como una aventura con grandes momentos de esplendor y grandes momentos de crisis. No es sólo la historia de una nación, sino que implica varias naciones y pueblos" (p. 6).

Ahora bien, sabiendo grosso modo cómo el inglés llega a ser lo que es, sería banal socavar el orden natural del progresismo y la postmodernidad; lo que acarrea una aceptación y versatilidad por los usuarios de los idiomas. En definitiva, pretender y negar la existencia del inglés, es nublarse a la realidad de un mundo globalizado. Esto no significa que sin el uso de este idioma las personas no puedan subsistir, más cierto es que se recortan las probabilidades de inserción social en múltiples ámbitos, para aquellas personas que deciden evitarlo. Con relación a lo anterior, Petuya Feito (2005) menciona que "El inglés es el idioma más hablado en el mundo. Es lengua oficial en más de cincuenta países y se habla en todos los continentes del mundo, incluyendo algunas estaciones en la Antártida" (p. 34). Además, vale la pena añadir que, efectivamente, saber inglés es fundamental hoy en día, tanto para entenderse cuando se viaja como para la mayoría de los trabajos (Winshley, 2012).

La última etapa de esta revisión de la literatura se centra en las profesionales de educación preescolar; las personas impulsoras de la educación infantil que sientan las bases, eminentemente junto con las familias, del desarrollo de las dimensiones de cada niño y niña. Sobre lo anterior, Morrison (2005) expresa que "Los padres y los profesores de preescolar pueden ayudar a los niños a realizar cambios fácilmente y con confianza en varios sentidos" (p. 291). Si bien parece ser cierto que los maestros y maestras de educación preescolar deben contar con una serie de actitudes que les permita ser idóneos para la labor en el trabajo con niños y niñas, también es cierto que debe haber una tarea mancomunada entre hogar e institución educativa. El profesorado no es el artífice, ni mucho menos, de todo lo que concierne a la formación del ser humano; no obstante, los conocimientos que poseen sobre la psicología de la niñez, su desarrollo humano y comportamiento, los hace acreedores de una gran responsabilidad en el sector de la sociedad: 
http://doi.org/10.15359/ree.26-1.18

Conocer a los niños -cómo crecen, cómo son, cómo piensan y sienten, cómo se relacionan con los demás- es prioridad del trabajo docente. Las y los maestros de educación preescolar serán capaces de usar ese saber como guía de su intervención pedagógica. (López Sánchez et al., 2007, p. 26)

Por lo regular, algunos artículos son muy expeditos clasificando a la educación preescolar como una etapa en la que la niñez va a recrearse y entretenerse; sin embargo, el juego, sin menospreciarlo, debe ser considerado un medio más, no un fin:

Por lo menos en sus planteamientos teóricos y metodológicos, han superado con un amplio margen al estereotipo de que el preescolar es un lugar para que "los niños jueguen y se entretengan antes de ingresar a la primaria", sustituyéndolo por la idea de que es un espacio necesario e idóneo para propiciar el desarrollo del niño. (Pérez Alarcón et al., 2002, p. 11)

Esta previa conceptualización ad hominem le posibilitará al lector tener un mejor entendimiento a lo largo de este escrito; mejores elementos para comprender la difusión de los resultados al igual que la etapa de discusión.

\section{Diseño y metodología}

En primera instancia, es necesario referir que esta investigación tuvo como objetivo general, el hecho de comprender la formación pedagógica de maestros de educación preescolar y su incidencia en los procederes didácticos en relación a una lengua extranjera en un ámbito internacional. Asimismo, entre los objetivos específicos se detallan los siguientes:

- Describir los escenarios de aprendizaje relacionados con la formación didácticopedagógica de maestros de preescolar.

- Detallar las estrategias metodológicas de aprendizaje y su incidencia en la formación didáctico-pedagógica de maestros de preescolar.

- Caracterizar la forma interactiva que se da entre la persona educadora y sus estudiantes en relación con la formación didáctico-pedagógica de maestros de preescolar.

De igual forma, para esta investigación, las personas participantes seleccionadas en Colombia fueron 100 docentes de educación preescolar, certificadas en 5 universidades distintas; todas del sector público y privado. Similarmente, quienes participaron por Chile fueron la misma cantidad, ubicadas todas en la región del Maule.

Primeramente, para este proyecto y su ejecución, la base fundamental fue el paradigma cualitativo, debido a que se hacía menester llevar a cabo una descripción y entendimiento detallado de la propuesta didáctica empleada por las participantes del estudio per se desde distintas perspectivas: 
Las reflexiones de tipo cuantitativo permiten conocer información importante a la hora de saber algo sobre determinado grupo, escenario, texto, o contexto. En este sentido, se consideró necesario vincular la investigación a esta forma de ver la realidad, teniendo en cuenta que esta busca, en vez de datos cerrados y consideraciones últimas, el análisis de fenómenos móviles, sucesos dinámicos y en constante transformación. (Jaramillo Valencia y Betancur Buitrago, 2019, p. 25)

Aún así, para dar producto a la información, se recurre a técnicas de aspecto cualitativo y cuantitativo, tales como entrevistas semiestructuradas y grupos focales; por lo cual, como ejemplo en el apartado de resultados, se podrán apreciar las Figuras 1 y 2 derivadas de la aplicación de los instrumentos de recolección de información.

Luego de aplicar las técnicas de recogida, la información fue recolectada y posteriormente codificada a través del software atlas ti, el cual posibilitó la interpretación gracias al uso de matrices categoriales, por medio de la triangulación de la documentación obtenida por los instrumentos per se, estos fueron: observación participante, grupo focal, encuesta y entrevista.

Asimismo, para esta investigación se tomaron dos muestras de referencia, una en Colombia y la otra en Chile. En la primera fueron maestras de preescolar del municipio de Medellín, 100 profesionales en educación preescolar o parvularia, graduadas de 5 universidades distintas. Para Chile, se selecciona una muestra de igual cantidad; es decir, maestras de una Universidad Regional de Docencia de la región del Maule. Todas las profesionales debieron atender a los siguientes requisitos (criterios de selección): Haber tenido más de un año de experiencia en educación preescolar y menos de cinco, haber trabajado con niñez no mayor de 5 años; y también, haber obtenido una titulación profesional en universidad del país posterior al año 2006.

\section{Resultados}

El objetivo principal en esta sección es mostrar los resultados cuantitativos de la categoría formación de las personas profesionales en educación preescolar o parvularia en la didáctica del inglés desde la universidad.

Primeramente, se procederá a presentar los figuras resultantes de las encuestas, dando luz a la pregunta: ¿La universidad otorga una formación adecuada a las personas profesionales en educación preescolar o parvularia en lo referente a la enseñanza del inglés?

En la Figura 1, se puede apreciar que de 100 profesionales de educación preescolar que participaron en la encuesta, el 3\% dijo estar totalmente de acuerdo en lo que a formación en enseñanza del inglés se refiere por parte de la universidad, un $8 \%$ expresó no estar de acuerdo ni en desacuerdo, el 19\% manifestó estar de acuerdo y un 22\% dijo estar totalmente en desacuerdo. Por último, el 38\% declaró estar en desacuerdo. 
http://doi.org/10.15359/ree.26-1.18

http://www.una.ac.cr/educare educare@una.ac.cr

Figura 1: Formación didáctica en la enseñanza del inglés, Colombia

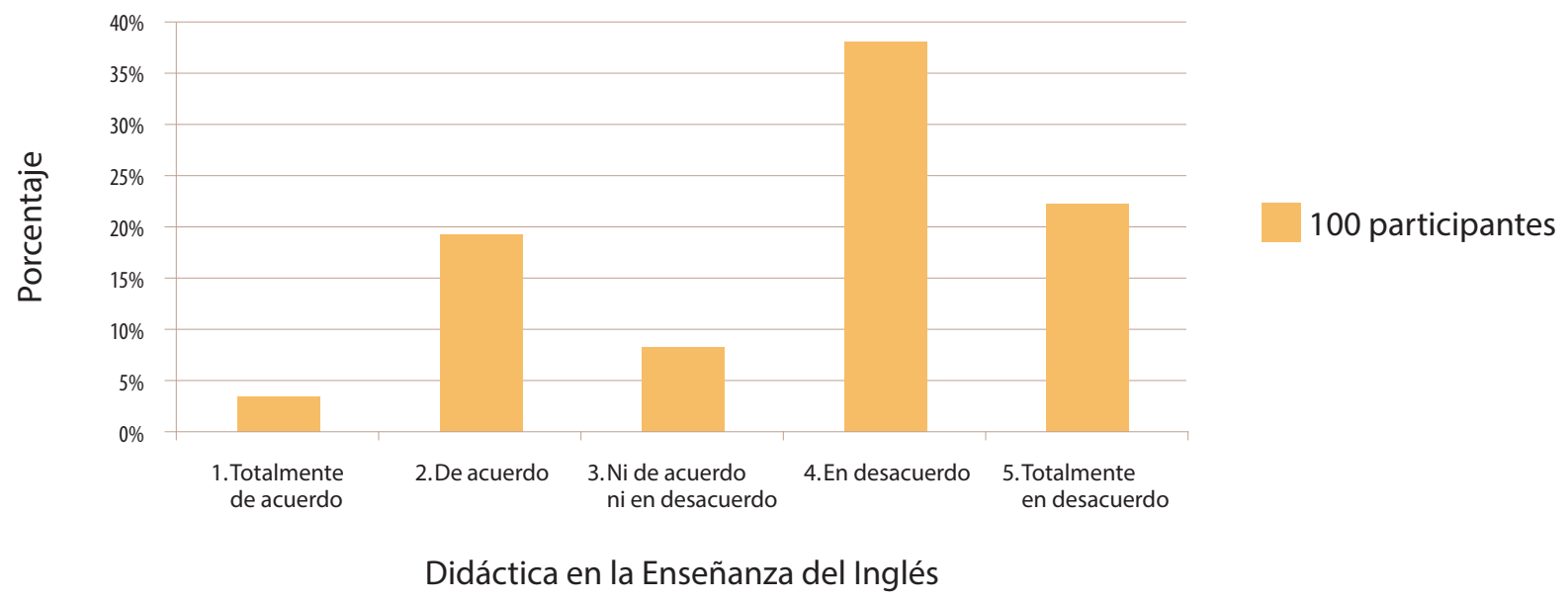

Nota: Elaboración propia con base en encuesta realizada a cien profesionales de educación preescolar en Medellín, Colombia, marzo 2018.

En esta Figura 1, las puntuaciones más elevadas están en las respuestas en desacuerdo y totalmente en desacuerdo, algo no muy distinto a las proporciones evidenciadas en las respuestas de las personas profesionales de educación parvularia en Chile.

En la Figura 2, se puede observar la exhibición de los datos de cinco categorías desarrolladas en Chile a maestras de educación preescolar o parvularia y a su formación pedagógica. No obstante, cuando se observa la categoría referente a la formación didáctica del inglés (lengua extranjera), se puede distinguir que un $6 \%$ manifiesta estar totalmente en desacuerdo en lo que a formación en enseñanza del inglés se refiere por parte de la universidad; asimismo, un 12\% dice estar totalmente en desacuerdo. Un 23\% manifiesta estar de acuerdo y un $27 \%$ estar en desacuerdo. Por último, un 32\% declaró no estar de acuerdo ni en desacuerdo.

Con base en lo que se muestra en las Figuras 1 y 2 , tanto en Colombia como en Chile las personas profesionales de educación preescolar o parvularia que participaron en este estudio escogieron, mayormente, la alternativa En desacuerdo; en Colombia un $38 \%$ y en Chile un $27 \%$. Datos que se incorporan a las entrevistas, grupos focales y talleres que se aplicaron para obtener información de corte cualitativa. 
http://doi.org/10.15359/ree.26-1.18

http://www.una.ac.cr/educare

educare@una.ac.cr

Figura 2: Formación general sobre pedagogía en profesionales educación preescolar o parvularia, Chile

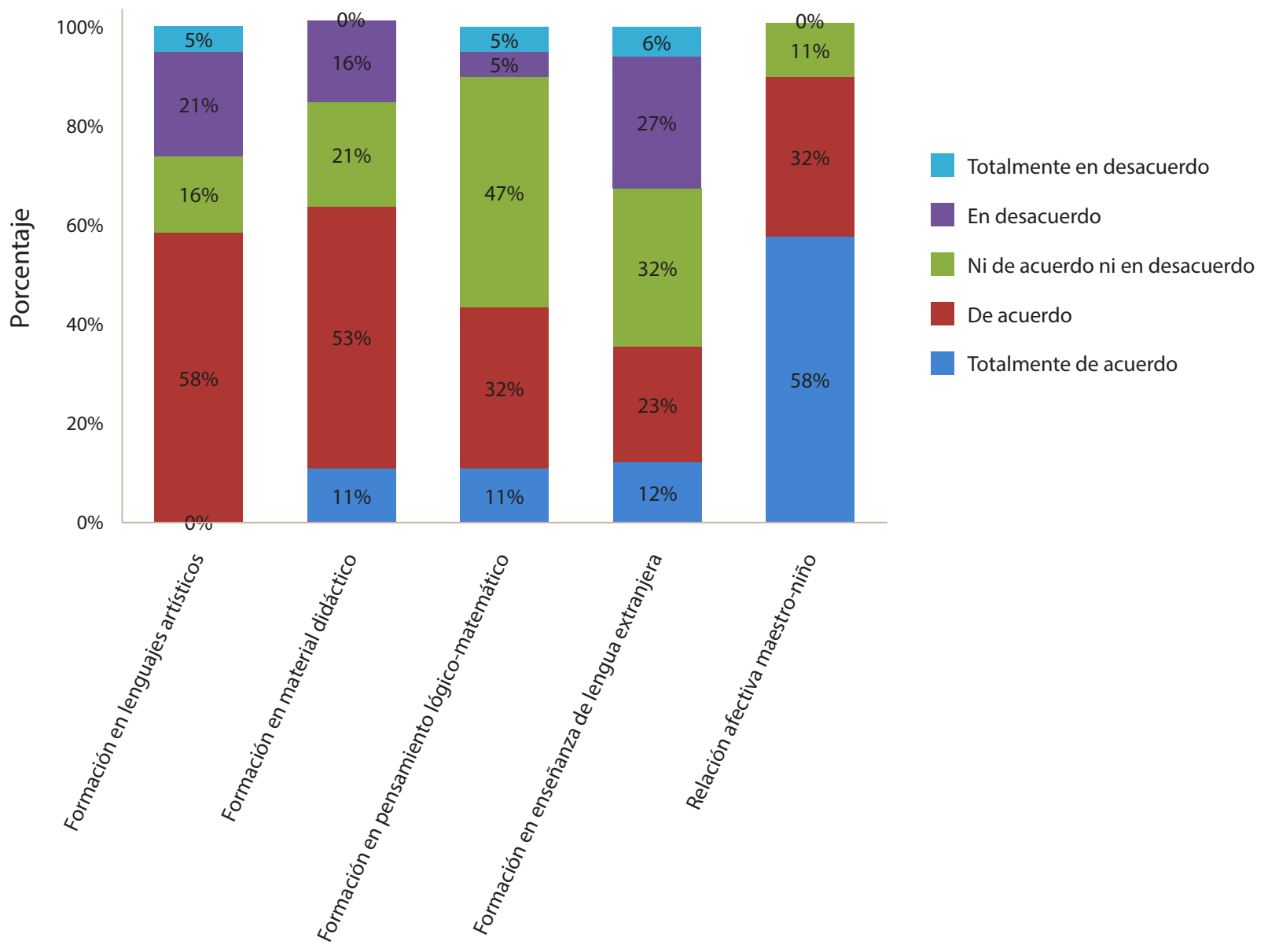

Formación Pedagógica en Educación Preescolar

Nota: Elaboración propia con base en encuesta realizada a cien profesionales de educación preescolar en el Maule, Chile, abril 2018.

\section{Discusión de los resultados}

En primera instancia, se agradece la deferencia que tuvieron las participantes de este estudio $y$, asimismo, la disposición para contestar y hacer parte del diálogo constructivo que permitió tener elementos sustantivos para esta sección. De este modo, se da comienzo con el tópico referente a la preparación de las docentes de educación preescolar por parte de la universidad en relación a la enseñanza del inglés para la niñez que cursan este nivel educativo. Con base en lo anterior, una de las profesoras que cooperó en las contestaciones de un grupo focal manifestó: 
http://doi.org/10.15359/ree.26-1.18

http://www.una.ac.cr/educare educare@una.ac.cr

Laverdadesquelauniversidadseesforzóparaprepararnos muybien en todos los componentes; de todas maneras, yo considero que a todas las que nos graduamos en ese periodo nos tocó asumir la responsabilidad de saber cómo enseñarles a los niños el idioma inglés. (Maestra entrevistada, comunicación personal, 17 de mayo, 2018)

En la anterior respuesta se puede percibir cómo la universidad, probablemente, pudo ser más clara o precisa al momento de proveer cursos intrínsecamente relacionados con la enseñanza del inglés para niños y niñas a maestras de preescolar en formación. Dichos cursos, normalmente, pudieron estar disponibles para el estudiantado de pregrado que pretendían llegar a ser profesores de inglés, mas no para estudiantes de otras carreras universitarias. En un estudio que se llevó a cabo en México sobre la enseñanza del inglés en instituciones de educación superior se llegó a la conclusión de que, "Es mayor la responsabilidad en las Instituciones formadoras de docentes porque de acuerdo a la reforma educativa, éstas en un futuro muy cercano tendrán la responsabilidad de enseñar a los niños el idioma inglés desde el nivel preescolar" (Zapata Pereyra y Orellana López., 2017, p. 2).

El trabajo de la enseñanza a la niñez, el cual exige del personal docente sus respectivas capacidades mentales, es, como ejemplo paradigmático, una ardua labor. Ahora bien, el inglés, tanto para aprenderlo como para enseñarlo, llega a ser un problema cuando no se cuenta con el saber apropiado. Erróneamente se puede creer que una persona profesional en educación preescolar no necesita asistir en la universidad a cursos que atañen a la didáctica de la enseñanza de una lengua extranjera (inglés) en las primeras edades; y más aún, este tipo de materias son de exclusividad para el estudiantado de licenciatura en inglés. Entonces, es cierto que estos están disponibles para el estudiantado de otras profesiones; sin embargo, son considerados cursos electivos, los cuales no son requisito y más bien opcionales, y dichas opciones rara vez son apetecidas por estudiantes de otras carreras que consideran el inglés un relleno y no algo útil en sus vidas. Acto seguido, otra profesional de educación preescolar que participaron en uno de los talleres, declaró lo siguiente:

No se puede negar que en la universidad asistimos a unos componentes de inglés, pero no eran sobre enseñanza a niños, más bien eran niveles para nosotras aprender. Y luego, ahora ya trabajando, toca indagar por material en internet para enseñarles a los niños, o también, con los profesores que enseñan ingles en el colegio uno se guía y ellos amablemente colaboran. (Maestra entrevistada, comunicación personal, 24 de mayo, 2018)

Lo que anteriormente se evidenció, fue algo recurrente en las personas profesionales que participaron en las entrevistas, ya que, aunque era mencionado de múltiples formas, declaraban tener los mismos traspiés en cuanto a la enseñanza del inglés se refiere: 
http://doi.org/10.15359/ree.26-1.18

http://www.una.ac.cr/educare

educare@una.ac.cr

Yo estudié en una universidad que, de pronto, nos pudo preparar más en ese tema de la enseñanza del inglés, yo pienso que el idioma inglés es más importante ahora que antes, pero también pienso que no es realmente el caso, ya que muchas de las profesoras que son egresadas de hace poco, y que comienzan a trabajar con nosotras en el colegio, también se les ve que se les dificulta enseñar ese idioma a los niños. (Maestra entrevistada, comunicación personal, 10 de mayo, 2018)

Si se observa bien, es posible notar que esta es una muestra manifiesta, la cual puede ser solucionada desde muchos aspectos, uno de ellos desde los cambios que se ejecuten en los currículos y planes de estudio para las personas profesionales en formación de licenciatura en educación preescolar, propiciándoles más elementos para enseñar a niños y niñas, una segunda lengua desde el preescolar. En una investigación que se llevó a cabo en Costa Rica sobre la formación docente en educación preescolar se evidenció lo siguiente, "Además, en muchos de los centros privados se pide a las maestras un perfil más 'academicista' y enfocado en la lecto-escritura, así como el manejo del inglés, la computación y la formación en especialidades profesionales" (Rojas, 2008, p. 151).

Contemplando esta realidad se percibe una imagen de puerta que se cierra, debido a la escasez de oportunidades para con las profesoras de preescolar en el momento de adquirir un trabajo, puesto que las familias son conscientes de cuán importante es el inglés actualmente, exigiendo en este sentido que el profesorado para sus niños tenga un nivel alto en esta segunda lengua, para que así sus hijos e hijas comiencen a adquirir estas habilidades lingüísticas desde las primeras edades. Es por eso que algunas instituciones educativas que brindan educación infantil se decantan por la contratación de profesorado con buenas capacidades en el dominio del inglés, ignorando la formación e idoneidad con la que cuenta el profesorado de preescolar para enseñar a esta población, pero que, por múltiples factores, no cuentan con un buen nivel en el manejo del idioma inglés. Con base en lo anteriormente mencionado, una profesional que participó en un grupo focal dijo:

Yo recuerdo que antes de trabajar en la escuela donde estoy ahora, me presenté a varias entrevistas para dar clase en preescolar o transición, y en una que otra me preguntaban si sabía hablar inglés y, además, si ya había enseñado inglés a esta población anteriormente. (Maestra entrevistada, comunicación personal, 17 de mayo, 2018)

Esta aseveración es convalidada por una investigación que se llevó a cabo en Santa Marta sobre la identidad personal y profesional del personal docente de preescolar de ese distrito, en la cual los padres y madres de familia evidenciaban sus aspiraciones en lo referente al aprendizaje de sus hijos e hijas; ellos pedían que la escuela como tal brindara "Una educación creativa que motive al niño a participar en el proceso de aprendizaje. Que dedique un tiempo justo para preescolar e incremente las clases de inglés e informática" (Mieles-Barrera et al., 2009, p. 58). 
http://doi.org/10.15359/ree.26-1.18

Con base en lo anterior, tiene más opciones de optar por un cargo para enseñar a la niñez aquella persona que tiene buen dominio del inglés, en comparación con la persona profesional en educación preescolar que cuenta con todos los elementos para llevar a cabo dicha labor:

Antes de estar trabajando aquí, me acuerdo que yo estuve en muchas entrevistas de trabajo en preescolares y me quedaban de llamar, después en la calle, con el tiempo, me topaba con colegas que ya se encontraban trabajando en dichos lugares; varias de ellas profesoras de inglés enseñando a niños de preescolar y transición, que no necesitaron pasar cinco años en una universidad viendo cursos sobre cómo hacer que los niños aprendan, cursos sobre manejo de padres, sobre necesidades educativas, etc. (Maestra entrevistada, comunicación personal, 17 de mayo, 2018)

En algunas ocasiones, la falta de epistemología, inexorablemente, se ve reflejada en la planeación, la didáctica y las estrategias metodológicas que el personal docente lleva a cabo en el aula de clase. Es necesario yacer con el conocimiento, hacerlo propio para enseñar una disciplina, lengua, ciencia, etcétera. De lo contrario, el docente y la docente no tienen otra opción que preguntar a colegas o buscar en otras fuentes para subsanar ese vacío pedagógico que padecerán los niños y las niñas en el aula de clase:

Cuando estudie en la universidad, vimos solamente unos niveles de inglés, pero estos cursos no tenían nada que ver con enseñanza del inglés a niños. Cuando en los últimos semestres comencé las prácticas, me percaté que debía enfatizar en eso. Además, en las entrevistas después de haberme graduado, me preguntaban por mi nivel de inglés, entonces fui a un centro de idiomas a adquirirlo, pero allí tampoco enseñaban cómo enseñar inglés a niños. Finalmente, le preguntamos a Google... (Maestra entrevistada, comunicación personal, 24 de mayo, 2018)

Parece ser que el desconocimiento sobre algo, así como lo referente a la enseñanza, es equivalente a la búsqueda de recursos digitales en la red, una forma no muy original pero práctica para muchas personas docentes. Al respecto, se manifiesta lo siguiente:

Mi preocupación es que los maestros que saben cómo enseñar, pero no saben cómo enseñar inglés, no serán capaces de educar a los niños como usuarios de la lengua. Por el contrario, los maestros que desde la teoría estén aprendiendo acerca de la metodología de la enseñanza de inglés como lengua extranjera no serán, necesariamente, mejores maestros de la lengua. (Clavijo Olarte, 2016, p. 9)

Cuando este fenómeno de desconocimiento epistemológico se manifiesta, aparece también el eclecticismo involuntario, una habilidad que se lleva a cabo en la práctica docente y que escasea concepto y teoría sobre la educación. Con base en lo anterior, Jaramillo Valencia (2012) menciona que: "Una propuesta ecléctica no puede entenderse como 'tomar de lo que me sirva', pues, el eclecticismo va más allá de la combinación sintético-analítica de los métodos" (p. 27). 
http://doi.org/10.15359/ree.26-1.18

http://www.una.ac.cr/educare

educare@una.ac.cr

Para concluir, es muy importante tener conciencia sobre las diferencias contextuales. Es decir, si bien el español y el inglés son dos lenguas que comparten el sistema alfabético -y aparentemente pueden ser desarrolladas de forma similar- no todos los aprendices tienen la posibilidad de potenciar sus competencias lingüísticas en casa u otros escenarios de aprendizaje, al margen de la escuela. Por lo cual, en tanto en Colombia como en México el inglés parece tomar más tiempo en ser dominado por un usuario del lenguaje en comparación al español:

Sin embargo, la mayoría de colombianos carece de contacto con el inglés en su vida diaria. A menudo se hacen asociaciones positivas entre el idioma inglés y el acceso a los medios globales. Sin embargo, para muchos colombianos esto es bastante limitado en la realidad, y el inglés no es parte integral de su vida diaria o profesional. (British Council, 2015, p. 56)

Cuando la persona profesional en educación preescolar realiza su profesión concienzudamente, el potencial beneficiado será el estudiantado. De esta forma, el eclecticismo involuntario se daría en menor frecuencia si la universidad tuviese en cuenta, un poco más, las necesidades sociales de los entornos escolares. Espacios que pide el personal docente cada vez más versátil y cualificado.

\section{Conclusiones}

En Colombia, algunas universidades deben implementar un curso sobre la didáctica del inglés enfocada en niños y niñas, específicamente en los planes de estudio para profesores en formación de educación inicial; es decir, implementarlo como una materia primordial en el pensum, en vez de ofrecerlo como un componente electivo.

Algunas instituciones educativas que imparten educación preescolar en Colombia, deberían seleccionar en sus contrataciones, personal idóneo para enseñar cada disciplina y población, es por eso que la personal profesional en educación inicial se enfoca en la enseñanza a niños y niñas partiendo desde todas sus dimensiones; por otro lado, el profesorado de inglés que se enfatiza en la enseñanza de dicha lengua, aunque puede enseñar a niños y niñas, cuenta con una capacitación no tan extensa y específica en lo referente a la enseñanza a esta población.

En Colombia, el personal docente de educación inicial que recibió el certificado English Proficiency, luego de haber cursado ya la universidad, no pudieron desarrollar en esos centros de idiomas, destrezas relacionadas al saber didáctico-pedagógico en la enseñanza del inglés a niñas y niños. Se sugiere que tomen cursos por extensión que ofrecen instituciones de educación superior para equiparar esa faltante, resultante de sus respectivos estudios durante el pregrado.

Los saberes tocantes a teorías, métodos y enfoques pedagógicos, parecen no ser suficientes al momento que este personal docente de educación inicial enseña a desarrollar la lengua inglesa en sus aprendices; en cambio, complementan esta necesidad con la búsqueda 
http://doi.org/10.15359/ree.26-1.18

http://www.una.ac.cr/educare educare@una.ac.cr

de información en diversas fuentes, entre estas, la internet. Se sugiere, entonces, tomar cursos, con intensidad horaria establecida, sobre didáctica para la enseñanza del inglés a niños y niñas, puesto que la búsqueda en internet, aunque es rápida y útil, ofrece una solución momentánea y, normalmente, con poco sustento epistemológico.

\section{Declaración de procedencia}

Este artículo es el resultante de la investigación“Formación pedagógica de los profesionales en educación inicial y su relación con la didáctica en un contexto internacional". El estudio se llevó a cabo por convocatoria externa de la Universidad Católica Luis Amigó y colaboraron otras entidades: La Universidad del Maule (Chile) y la Red Iberoamericana de Pedagogía. Este proyecto dio inicio el día febrero 1 de 2018 y terminó el 30 de noviembre de 2018.

\section{Declaración de Material complementario}

Este artículo tiene disponible, como material complementario:

-La versión preprint del artículo en https://doi.org/10.5281/zenodo.4891708

\section{Referencias}

British Council. (2015). El inglés en Colombia: Estudio de políticas, percepciones y factores influyentes. Inteligencia Educativa.

Carro, J. M. (2011). Inglés en español. Lulu.com

Casares Domingo, S. (2006). Atlas básico de inglés. Parramón.

Cifuentes Londoño, M. A., Martínez Guerra, L. M., Jaramillo Valencia, B., Cardona Muñoz, N. B. y Jiménez Herrera, S. A. (2019). Entre la oferta y la demanda: El idioma inglés visto como una barrera invisible que interfiere en el acceso a la labor docente de las profesionales en educación inicial. En C. A. Silva Giraldo (Coord.) Retos y desafíos perspectivas de la educación y la empresa (Vol. 1, pp. 8-21). EIDEC.

Clavijo Olarte, A. (2016). La enseñanza del inglés en la escuela primaria: Algunos problemas críticos. Colombian Applied Linguistics Journal, 18(1), 9-10. https://www.redalyc.org/ pdf/3057/305745627001.pdf

Díaz Alcaraz, F. (2002). Didáctica y currículo: Un enfoque constructivista. Ediciones de la Universidad Castilla-La Mancha. 
http://doi.org/10.15359/ree.26-1.18

http://www.una.ac.cr/educare

educare@una.ac.cr

Freire, P. (1994). Cartas a quien pretende enseñar. Siglo XXI.

Espinosa Jiménez M. (2018). Didactoeugenia. La buena práctica docente en la enseñanza. Revista Panamericana de Pedagogía. Saberes y Quehaceres del Pedagogo, (25), 141-152. https://revistas.up.edu.mx/RPP/article/view/1734

Jaramillo Valencia, J. (2012). Enseñanza de la lectura: Desencuentros entre teoría y práctica. La Voz del Semillero, (5), 17-28. https://www.funlam.edu.co/uploads/centroinvestigaciones/ publicaciones/la.voz.del.semillero.No5.pdf

Jaramillo Valencia, B. y Betancur Buitrago, B. (2019). Dimensión estética en la enseñanza de la filosofía: Posibilidades de sensibilización frente a la diversidad ideológica en el posconflicto colombiano. Perseitas, 7(1), 18-39. https://doi.org/10.21501/23461780.3155

Jaramillo Valencia, B. y Quintero, S. y (2018). La didáctica en profesores de educación parvularia o preescolar: Los casos de Colombia y Chile. En E. Serna (Ed.), Revolución en la formación y la capacitación para el siglo XXI (pp. 86-93). Editorial Instituto Antioqueño de Investigación. https://www.researchgate.net/publication/329103586 La didactica en profesores de educacion_parvularia_o preescolar_Los_casos_de_Colombia_y_Chile

Laudo Castillo, X., Esteruelas i Teixidó, A. E., Moreu Calvo, Á. C. y Prats Gil, E. (2017). La esencia de enseñar en la universidad. Una aproximación fenomenológica. En X. Laudo Castillo e I. Vilafranca Manguán (Coord.), ¿Enseñar y aprender en la universidad? Ensayos fenomenológicos y hermenéuticos (pp. 71-90). Edicions Universitat Barcelona.

Llera, J. B. (1995). 1. Naturaleza, desarrollo y contenido de la psicología de la educación. En J. B. llera y J. A. Bueno Álvarez (Eds.), Psicología de la educación (pp. 3-24). Marcombo.

López Sánchez, J., Elizalde Trinidad, A. y Mejía Mejía, M. L. (2007). Educar en y para la diversidad en el nivel preescolar. Secretaría de Educación Pública.

Mieles-Barrera, M. D., Henríquez-Linero, I. M.y Sánchez-Castellón, L. M. (2009). Identidad personal y profesional de los docentes de preescolar en el distrito de Santa Marta. Educación y Educadores, 12(1), 43-59. https://dialnet.unirioja.es/descarga/articulo/2983790.pdf

Morrison, G. S. (2005). Educación infantil. Pearson Educación.

Abreu, O., Gallegos, M. C., Jácome, J. G. y Martínez, R. J. (2017). La didáctica: Epistemología y definición en la Facultad de Ciencias Administrativas y Económicas de la universidad Técnica del Norte del Ecuador. Formación Universitaria, 10(3), 81-92. https://bit.ly/3D8DwEO

Orellana-Fernández, R., Merellano-Navarro, E. y Almonacid-Fierro, A. (2018). Buen o buena docente de universidad: Perspectiva del personal directivo de carrera y de los mismos grupos docentes. Revista Electrónica Educare, 22(2), 1-27. https://doi.org/10.15359/ree.22-2.6 
http://doi.org/10.15359/ree.26-1.18

http://www.una.ac.cr/educare educare@una.ac.cr

Pérez Alarcón, J., Abiega, L., Zarco, M. y Schugurensky. (2002). Nezahualpilli. Educación preescolar comunitaria. Plaza y Valdes editores.

Petuya Feito, A. (2005). Inlgés A1. Ideaspropias Editorial.

Picado Godínez, F. M. (2006). Didáctica general: Una perspectiva integradora. EUNED.

Rojas, R. (2008). La formación docente en educación preescolar en Costa Rica y su pertinencia social. Posgrado y Sociedad, 8(1), 131-165. https://dialnet.unirioja.es/servlet/ articulo?codigo $=3662624$

Rojas-Jara, C., Díaz-Larenas, C., Vergara-Morales, J., Alarcón-Hernández, P. y Ortiz-Navarrete, M. (2016). Estilos de enseñanza y estilos de aprendizaje en educación superior: Análisis de las preferencias de estudiantes de Pedagogía en Inglés en tres universidades chilenas. Revista Electrónica Educare, 20(3), 1-29. https://doi.org/10.15359/ree.20-3.7

Soto-Grant, A. (2018) Habilidades y estrategias didácticas necesarias para la alfabetización visual en educación preescolar. Revista Electrónica Educare, 22(3), 1-7. https://doi.org/10.15359/ ree.22-3.2

Winshley, J. (2012). Inglés exprés. Inglés de Base. De Vecchi Ediciones.

Zapata Pereyra, M. T. y Orellana y López, M. de los D. (2017). Estado del conocimiento de la enseñanza del inglés en instituciones de educación superior. International Journal of Humanities and Social Science Invention, 6(6), 01-04. http://www.ijhssi.org/papers/v6(6)/ Version-4/A0606040104.pdf 